\title{
FACTORS IMPACTING KNOWLEDGE TRANSFER SUCCESS IN INFORMATION SYSTEMS OUTSOURCING
}

\author{
Zahran Al-Salti, Information Systems Evaluation and Integration Group (ISEing) \\ Brunel Business School, Brunel University, UK \\ zahran.al-salti@brunel.ac.uk \\ Ray Hackney, Information Systems Evaluation and Integration Group (ISEing) \\ Brunel Business School, Brunel University, UK \\ ray.hackney@brunel.ac.uk \\ Sevgi Özkan, Informatics Institute \\ Middle East Technical University, Turkey \\ sozkan@ii.metu.edu.tr
}

\begin{abstract}
Despite increased research interest on knowledge transfer in information systems (IS) outsourcing, the field still lacks sound and holistic understanding of the key factors influencing knowledge transfer success. The present paper attempts to provide a synthesis of existing theoretical perspectives and empirical findings related to the factors that facilitate or hamper knowledge transfer success in IS outsourcing. The data collection method is discussed and the key findings are presented. Conclusion is drawn and further research is suggested.
\end{abstract}

Keywords: knowledge transfer, Information systems (IS) outsourcing

\section{BACKGROUND}

In today's knowledge-based economy, one of the major sources of competitive advantage has been the ability of the firm to transfer external knowledge efficiently and effectively (Argote and Ingram, 2000; Pawlowski and Robey, 2004; Sambamurthy and Subramani, 2005; PérezNordtvedt et al., 2008). Knowledge transfer is defined by Kumar and Ganesh (2009) as activities of exchanging explicit or tacit knowledge between two agents, during which one agent receive and apply the knowledge provided by the other agent. The agents could be an individual, team/department or an organization (Joshi et al., 2007). In the literature, knowledge transfer has been given various but related labels such as 'knowledge sharing, 'knowledge flows', 'knowledge acquisition' and 'knowledge mobilization' (Carmel and Nicholson, 2005; Gosain, 2007; Renzl, 2008; van Wijk et al, 2008).

Information systems (IS) outsourcing, where a client organization contract out some or all of its IS functions to one or more external vendors (Lee, 2001), has been regards as an important business strategy for client organizations to transfer new technical and business knowledge from the vendors (e.g. Ko et al., 2005; Tafti, 2007, Blumenberg et al., 2009). Wang et al. (2008) argued that outsourcing IS to high quality vendors has the potential to transfer knowledge that are costly or hard to develop in-house. Furthermore, IS outsourcing allows the client organizations to renew its technical and business knowledge base in order to achieve congruence with changing business environment (Bandyopadhyay and Pathak, 2007). In their 
study of knowledge transfer in enterprise resource planning (ERP) implementations, Ko et al. (2005) reported that client organizations acquire new implementation, operational and maintenance knowledge from their consultants, so they can learn and later maintain the system independent of the consultant's team. Edguer and Pervan (2004) found that many firms are increasingly looking at IS outsourcing as a means of transferring and leveraging the vendors' superior technical and business knowledge and benefiting complementary skills and specialist expertise that are not available within the organization's boundaries. Knowledge transfer from vendors to clients in IS outsourcing projects occur through a variety of mechanisms. These mechanisms include manuals, personal movement, training, observation, presentations and close interaction with vendors' IS staff (Nicholson and Sahay, 2004; Xu et al., 2006; Chua and Pan, 2008)

Knowledge transfer success has been defined in the literature using various approaches. One approach of defining transfer success is by measuring the number of knowledge transfers engaged during a certain period of time (Cummings and Teng, 2003). A second approach was suggested by Laframboise et al. (2007) as the one that is both effective (properly transmitted and used) and efficient (using minimal resources). A third approach to defining knowledge transfer is by assessing the extent to which the recipient perceives the knowledge transferred from the source as comprehensive, useful and satisfactory (Li and Hsieh, 2009). The success of knowledge transfer not only depends on the capability of the source to provide the necessary knowledge, but also on the characteristic of the knowledge (Argote et al., 2000; McEvily and Chakravarthy, 2002) and the intention and the ability of the receiver to absorb and utilize the transferred knowledge (Steensma and Lyles, 2000; Tsang, 2002; Zahra and George, 2002). Moreover, differences in cultures, structures and goals between the source and the recipient of knowledge may impede collaboration and consequently hinder knowledge transfer (Lee, 2001; Levina and Vaast, 2008; Salmi and Torkkeli, 2009).

In spite of the recognized importance and the potential value of knowledge transfer in IS outsourcing, little systematic and holistic research has been pursued to understand the key factors affecting knowledge transfer success from the vendors to the client in IS outsourcing (Joshi et al., 2007). Furthermore, without a comprehensible understanding about the key factors that contributes to effective knowledge transfer, managers are "left in the dark" as to what they can do to foster valuable knowledge transfer when outsourcing IS (Levin, et al., 2004, p. 36). Therefore, the aim of the present paper is to analysis the literature to answer the following question: What are the key factors that facilitate or inhibit knowledge transfer success from vendors to clients in IS outsourcing? In this study, the vendor (i.e. service provider) is the source of knowledge and the client (i.e. service receiver) is the recipient of knowledge. The remainder of the paper is laid out as follows. The next section describes the process of data collection and analysis. Afterwards, the key findings and discussion are presented. The Conclusion section covers contributions of this paper, implications and opportunities for future research.

\section{DATA COLLECTION AND ANALYSIS}

This study attempted to review the IS, knowledge management and strategic management literature that is mainly published in prestigious journals in the last nine years [2000-2009]. Books and press papers were excluded in this study. Only certain number of high profile related conferences was investigated. This is consistent with recommendation of Gonzalez et al. (2006) who carried out a review of IS outsourcing literature and argued that practitioners and academics prefer using 'high profile' journals to acquire and disseminate new knowledge. 
Major online databases such as ScienceDirect, ABI/ Inform, Business Source Premier and ACM Digital Library were searched for related articles. Index search of some leading IS and Knowledge Management journals such MISQ, Journal of Strategic Information Systems, Journal of Knowledge Management and Information \& Management was also carried out to identify key related articles. A keyword search method using a combination of search terms such as "knowledge transfer" and "IS outsourcing," or "knowledge transfer" and "IT outsourcing" was employed. The searches were limited to the period from January 2000 to December 2009 in order to extract relatively recent related articles. This search lead to the identification of 91 articles related to knowledge transfer in IS outsourcing.

Given the goal of this study is to gain a depth understanding of various factors already identified by other researchers, content analysis was deemed to be an appropriate analysis approach. This is consistent with recommendation of Silverman (2000) who argued that content analysis is the most appropriate technique for analyzing texts such as academic articles. Twenty articles (shown in Table 1) were found to contain discussion about some of the factors that impact knowledge transfer in IS outsourcing.

\section{FINDINGS AND DISCUSSION}

The compiled articles suggested that there are four main sets of factors that influence knowledge transfer success in IS outsourcing. These sets are: knowledge-related factors, recipient-related factors, source-related factors and relationship-related factors. Table 1 shows the key studies that have discussed some of the factors the influence knowledge transfer success in IS outsourcing. It is worth noting that some of these factors are labelled differently in the literature.

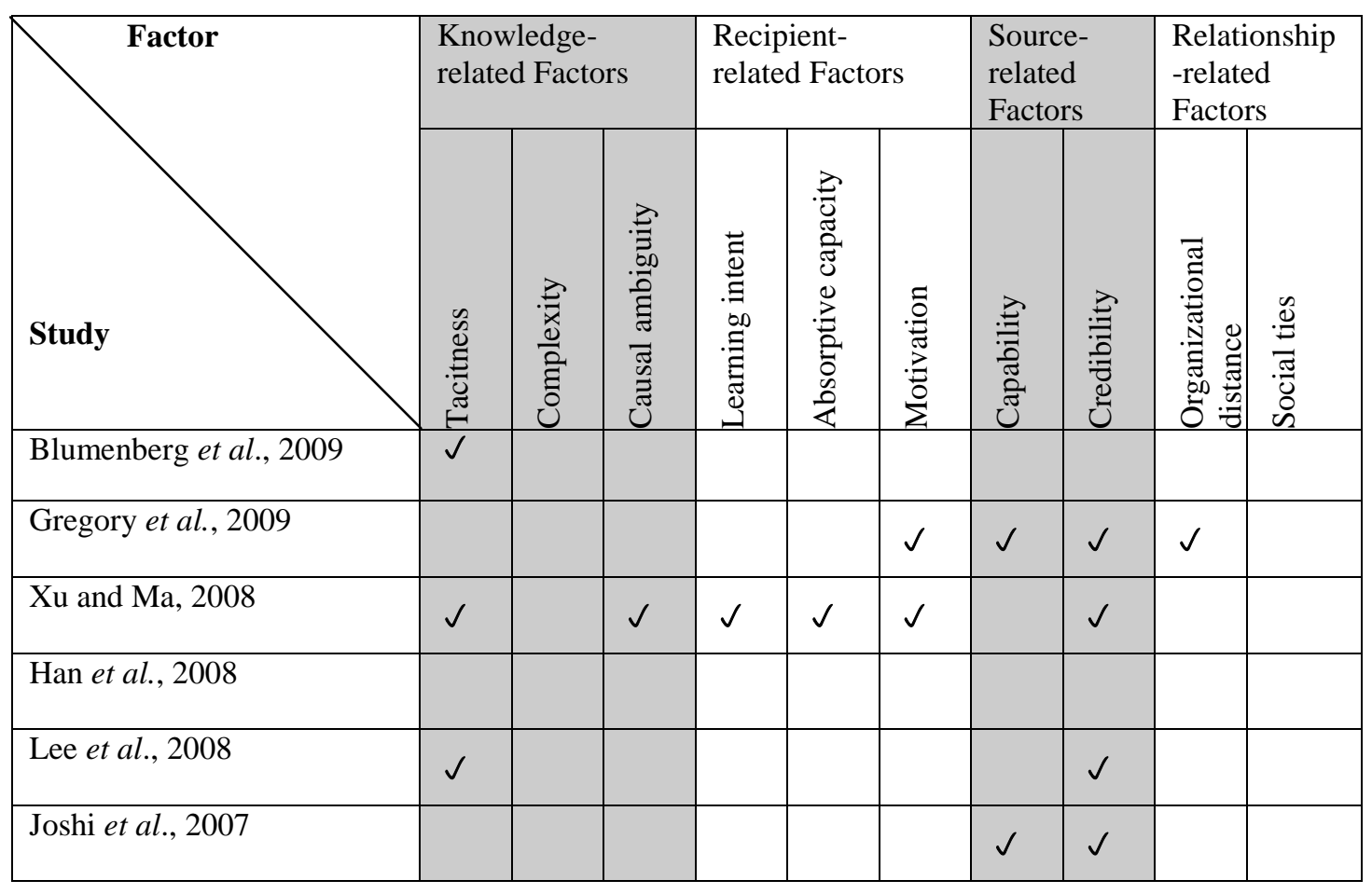




\begin{tabular}{|l|l|l|l|l|l|l|l|l|l|l|}
\hline Gosain, 2007 & $\checkmark$ & $\checkmark$ & & & & & & $\checkmark$ & & \\
\hline Wang et al., 2007 & & & & & $\checkmark$ & & $\checkmark$ & & & \\
\hline $\begin{array}{l}\text { Bandyopadhyay and Pathak, } \\
2007\end{array}$ & & & & $\checkmark$ & & & & & & \\
\hline $\begin{array}{l}\text { Srivardhana and Pawlowski, } \\
2007\end{array}$ & & & & & $\checkmark$ & & $\checkmark$ & & & \\
\hline Park et al., 2007 & & & & & $\checkmark$ & & & & & \\
\hline Pardo et al., 2006 & $\checkmark$ & $\checkmark$ & & & & $\checkmark$ & & $\checkmark$ & $\checkmark$ & \\
\hline Xu et al., 2006 & & & & & $\checkmark$ & & & & & \\
\hline Mirani, 2006 & & & & & & & & $\checkmark$ & $\checkmark$ & $\checkmark$ \\
\hline Ko et al., 2005 & & & & & $\checkmark$ & $\checkmark$ & & $\checkmark$ & & \\
\hline Imsland and Sahay, 2005 & $\checkmark$ & & & & & & & & $\checkmark$ & \\
\hline Sarker et al., 2005 & & & & & & & $\checkmark$ & $\checkmark$ & $\checkmark$ & $\checkmark$ \\
\hline Nicholson and Sahay, 2004 & $\checkmark$ & & & & & & & & $\checkmark$ & \\
\hline Lee, 2001 & $\checkmark$ & & & & $\checkmark$ & & & $\checkmark$ & & \\
\hline Timbrell et al., 2001 & & & $\checkmark$ & & $\checkmark$ & $\checkmark$ & & $\checkmark$ & & \\
\hline
\end{tabular}

Table 1: Factors influencing knowledge transfer success in IS outsourcing

\subsection{Knowledge-related}

The nature and the characteristics of the knowledge being transferred have been recognized as important factors that impact knowledge transfer success. Blumenberg et al., (2009) studied knowledge transfer process in IS outsourcing projects and found that knowledge transfer success is affected by the tacitness of the knowledge, or how easy or difficult it is to codify and articulate the knowledge that need to be transferred. Tacit knowledge is hard to be transferred verbally or in writing as it resides in the minds of people (Gottschalk, 2006; Hackney et al., 2008). The complexity of knowledge has also been regarded as a major impediment to the success of knowledge transfer. Knowledge complexity refers to the number of interdependent routines, individuals, technologies and resources linked to a particular knowledge (Gosain, 2007). Narteh (2008) contended that complex knowledge is likely to involve many interdependent components and may be difficult to be communicated between the source and the recipient. Causal ambiguity is another inhibitor of knowledge transfer success. Xu and Ma (2008, p. 529) defined causal ambiguity as "the lack of understanding of the logical linkage between action and outcomes, inputs and outputs, and causes and effects". Timbrell et al. (2001) examined the characteristics of knowledge in IS outsourcing projects in Australia and found that knowledge with high causal ambiguity is more challenging and much harder to transfer than less ambiguous knowledge. It can be concluded, therefore, that the greater the ambiguity of the causes and effects of the knowledge, the more difficult is to identify the related knowledge elements and subsequently the chances of transferring the knowledge are limited. 


\subsection{Recipient- related}

The transfer of knowledge depends not only on the characteristics of the knowledge transferred but also on the learning intent, absorptive capacity and motivation of the recipient of knowledge. Learning intent is the extent to which the receipt has the potential to learn and acquire new knowledge and skills proposed by the source (Tsang, 2002). Learning intent is found to enhance the amount of knowledge transferred (Narteh, 2008). If the recipient has a high learning intention and is very self-motivated to acquire knowledge possessed by the source, it will be better prepared psychologically to understand and assimilate the knowledge (Easterby-Smith et al., 2008). Bandyopadhyay and Pathak (2007) explored knowledge sharing in outsourcing project and found that knowledge sharing success depends on the learning intent of the recipient and the time and efforts employed to acquire the knowledge. Another factor that found to influence knowledge transfer success is absorptive capacity. Absorptive capacity is defined as the ability of the recipient to recognize the value of the new knowledge provided by the source, assimilate it and apply it to business ends (Schmidt, 2010). The study of Ko et al. (2005), mentioned above, explained how knowledge transfer success is much related to that capacity of the clients (recipient) to absorb the transferred ERP knowledge from the consultants (source) and effectively apply it to commercial ends. Zahra and George (2002), on the other hand, found that lack of absorptive capability is one of the primary factors that hamper knowledge transfer success. The underlying premise is that a recipient's stock of prior related knowledge and experience is essential to effectively absorb and utilize external knowledge (Srivardhana and Pawlowski, 2007). An important factor that has been identified by the literature to impact knowledge transfer success is the motivation of the recipient to explore and acquire valuable knowledge (Ko et al., 2005). Xu and Ma (2008) investigated the key determinants of ERP implementation knowledge transfer and found that the stronger the motivation to learn, the more likely it is that individuals will attempt to master and use new external knowledge. Motivations for transferring knowledge range from extrinsic incentives such as bonuses to intrinsic motivations such as praise and public recognition (Ko et al., 2005; Chua and Pan, 2008).

\subsection{Source-related}

The third set of factors is related to the source of the knowledge. The two factors that are identified in this set are called source capability and source credibility. Source capability is the extent to which the receipt views the source as capable and expert and has a wealthy technical and business knowledge-base (Joshi et al., 2007). Capable and committed source tend to devote time and resources to support the transfer of knowledge to the recipient (Ko et al., 2005; Gregory et al., 2009). Tan (2009) investigated the factors affecting IS outsourcing success and found that vendor capability is essential as a capable vendors tend to possess great reservoirs of knowledge, skills and expertise. A study by Wang et al. (2007, p. 206) on knowledge transfer in ERP implementation highlighted the importance of consultants' (i.e. source) capability "to offer related and needed knowledge, to mobilize various skills, and to help the client configure and derive value from the ERP package". Source credibility is also found to facilitate knowledge transfer. Joshi et al. (2007, p. 326) defined source credibility as "the extent to which a recipient perceive a source to be trustworthy and reputable". Trust is the believe that the source' word is reliable and that it will fulfil its obligation as stipulated in the agreement (Timbrell et al., 2001). Lee et al. (2008) investigated the impact of trust on IS outsourcing success and found that mutual trust facilitate knowledge sharing between vendors and clients. Reputation has been regarded as central for knowledge transfer success because it is often used in screening and 
evaluating the value of the source of knowledge (Joshi et al., 2007). Initiating a knowledge transfer from a credible and trustworthy source tend to be less challenging (Lander et al., 2004). However, in the absence of trust, recipient perceives a source's knowledge to be less valuable and not much persuasive (Ko et al., 2005).

\subsection{Relationship-related}

The nature of the relationship and the interaction between individuals of the client and the vendor organizations found to impact the effectiveness and the success of knowledge transfer in IS outsourcing (Ko et al., 2005). Ranft and Lord (2002) argued that many of the knowledge transfer difficulties stem from organizational issues and human resource conflicts between the source and the recipient of knowledge. The two key factors that have been identified are: organizational distance and social ties. Organizational distance measures the degree of organizational integration between the source and the recipient of knowledge (Cummings and Teng, 2003). The knowledge transfer literature identified three main types of organizational distance, namely physical distance, organizational culture distance and national culture distance.

Physical distance refers to the difficulty, time requirement and expense of communicating and getting together face-to-face (Cummings and Teng, 2003). Nicholson and Sahay (2004) studied knowledge transfer in software offshore outsourcing project between a British firm and an Indian vendor and found that geographical separation negatively influences knowledge transfer, resulting in serious misunderstanding. Organizational culture distance is the extent to which the source and the receipt of knowledge possess different work values, ideologies, norms and, problem-solving approaches (Ko et al., 2005). Difficulties in knowledge transfer tend to arise when there are differences in organizational culture. Krishna et al. (2004) explored the impact of organizational culture distance in IS offshore outsourcing between a Japanese client and an Indian vendor. The study revealed that Japanese take much longer time to reply to e-mails as compared to Indians, and this had negative impact on knowledge transfer between the two parties. National culture distance has been widely recognised as a major inhibitor for knowledge transfer between the source and the recipient in IS outsourcing, particularly when it comes to offshore outsourcing (Imsland and Sahay, 2005; Huang and Trauth, 2007). National culture distance is when the source and the recipient of knowledge lack a common language, values, beliefs and cultural background understanding (Narteh, 2008). Goles and Chen (2005) investigated the key relationship factors that impact IS outsourcing and found that cultural background difference and language incompatibility can be a major stumbling block for outsourcing relationships in general and knowledge transfer in particular. Therefore, it can be concluded that insufficient background about each other, lack of a common languages and cultural misunderstanding limits the ability of the client to transfer knowledge from the vendor in IS outsourcing.

Social ties has received a great deal of attention in inter-organizational collaboration literature (e.g. Adler and Kwon, 2002; Jasimuddin, 2007; Bell and Zaheer, 2007), particularly in knowledge intensive works such as IS outsourcing (e.g. Kotlarsky and Oshri, 2005). Oshri et al. (2007) conducted a qualitative case study to explore how globally distributed information systems development work is affected by socialization and face-to-face meetings. The study found that face-to-face meetings allow IS professionals from the client and vendor organizations to develop interpersonal relationship and therefore exchange knowledge informally. Other knowledge transfer studies emphasized the importance of personal ties in facilitating the communication of no-codified knowledge. For example, Blumenberg et al., (2009) suggested that frequent face-to-face interaction is crucial for transferring technical tacit knowledge in IS 
outsourcing projects. However, this demands a close partnership between the client and the vendor (Kern and Willcoks, 2000; Goles and Chen, 2005).

\section{CONCLUSION}

Although there is a drawing acknowledgment of the importance of knowledge transfer in IS outsourcing, very little is known about the key factors that determine the success of knowledge transfer from vendors to clients. This study has presented an attempt to review the literature in order to further deepening our understanding of the key factors that affect knowledge transfer success in IS outsourcing. The findings suggest that there are four set of factors: knowledgerelated, recipient-related, source-related and relationship-related that facilitate or inhibit knowledge transfer success. Although this paper does not claim to be exhaustive, the findings presented have several important implications for IS researchers and practitioners alike. This review of prior related studies attempts to set theoretical foundation for future research that should lead to the development of a multifaceted framework for knowledge transfer in IS outsourcing. This study also provides new insights and implication for manger of client organizations by raising their awareness of the critical factors that enable or inhibit knowledge transfer in IS outsourcing projects.

\section{References}

Adler, P. and Kwon, S. 2002. 'Social capital: prospects for a new concept'. Academy of Management Review, 27: 17-40.

Argote, I. and Ingram, P. 2000. 'Knowledge transfer: A basis for competitive advantage in firms'. Organizational Behaviour and Human Decision Processes, 82(1): 150-169.

Bandyopadhyay, S. and Pathak, P. 2007. 'Knowledge sharing and cooperation in outsourcing projects - A game theoretic analysis'. Decision Support Systems, 43(2): 349-358.

Bell, G. and Zaheer, A. 2007. 'Geography, networks, and knowledge flow'. Organization Science, 18: 955-72.

Blumenberg, S., Wagner, H. and Beimborn, D. 2009. 'Knowledge transfer processes in IT outsourcing relationships and their impact on shared knowledge and outsourcing performance'. International Journal of Information Management, 29 (5): 342-352.

Carmel, E. and Nicholson, B. 2005. 'Small firms and offshore software outsourcing: high transaction costs and their mitigation'. Journal of Global Information Management, 13(3): 33-54.

Chua, A. and Pan, S. 2008. 'Knowledge transfer and organizational learning in IS offshore outsourcing'. Omega, 36 (2): 267-281.

Cummings, J and Teng, B. 2003. 'Transferring R\&D knowledge: the key factors affecting knowledge transfer success'. Journal of Engineering and Technology Management. 20: 3968.

Easterby-Smith, M., Graça, M., Antonacopoulou, E. and Ferdinand, J. 2008. 'Absorptive capacity: A process perspective'. Management Learning, 39(5): 483-501

Edguer, E. and Pervan, G. 2004. 'Success factors and measures for public sector IS/IT cosourcing contracts'. Australasian Journal of Information Systems, 11 (2): 4-12.

Goles, T. and Chin, W. 2005. 'Information systems outsourcing relationship factors: detailed conceptualization and initial evidence'. The DATA BASE for Advances in Information Systems, 36 (4): 47-67. 
Gonzalez, R, .Gasco, J. and Llopis, J. 2006. 'Information systems outsourcing: A literature analysis. Information \& Management' 43 (7): 821-834.

Gosain, S. 2007. 'Mobilizing software expertise in personal knowledge exchanges'. Journal of Strategic Information Systems, 16 (3): 254-277.

Gottschalk, P. 2006. 'Research propositions for knowledge management systems supporting IT outsourcing relationships'. Journal of Computer Information Systems, 46 (3): 110-116.

Gregory, R., Beck, R. and Prifling, M. 2009. 'Breaching the knowledge transfer blockade in it offshore outsourcing projects: A case from the financial services industry'. Proceedings of the 42nd Hawaii International Conference on System Sciences. January 5-8, Wikoloa, Big Island, Hawaii.

Hackney, R., Desouza, K. and Irani, Z. 2008. 'Constructing and sustaining competitive interorganizational knowledge networks: an analysis of managerial web-based facilitation'. Information Systems Management Journal, 25(4): 356-363.

Han, H., Lee, J. and Seo, Y. 2008. 'Analyzing the impact of a firm's capability on outsourcing success: A process perspective'. Information \& Management, 45 (1): 31-42.

Huang , H. and Trauth , E. 2007 'Cultural influences and globally distributed information systems development: experiences from Chinese IT professionals'. Proceedings of ACM SIGMIS-CPR Conference, St Louis, Missouri, USA, April 2007 pp.36-45.

Imsland, V, and Sahay, S. 2005. 'Negotiating knowledge': The case of a Russian-Norwegian software outsourcing project'. Scandinavian Journal of Information Systems, 17(1):101-130.

Jasimuddin, S. 2007. 'Exploring knowledge transfer mechanisms: The case of a UK-based group within a high-tech global corporation'. International Journal of Information Management 27 (4): 294-300.

Joshi, K., Sarker, S. and Sarker, S. 2007. 'Knowledge transfer within information systems development teams: examining the role of knowledge source attributes'. Decision Support Systems. 43 (2): 322-335.

Kern, T. and Willcoks, L. 2000 'Exploring information technology outsourcing relationships: theory and practice'. Journal of Strategic Information Systems, 9 (4), 321-350.

Kotlarsky, J. and Oshri, I. 2005. 'Social ties, knowledge sharing and successful collaboration in globally distributed system development projects'. European Journal of Information Systems, 14(1): $37-48$

Krishna, S., Sahay, S. and Walsham, G. 2004. 'Managing cross-cultural issues in global software outsourcing'. Communications of the ACM, 47(4): 62-66.

Kumar, J. and Ganesh, L. 2009. 'Research on knowledge transfer in organizations: a morphology'. Journal of Knowledge Management, 13(4): 161-174.

Laframboise, K., Croteau, A., Beaudry, A and Manovas, M. 2007. 'Interdepartmental knowledge transfer success during information technology projects'. International Journal of Knowledge Management, 3 (2), 47-67.

Lander,C., Puvis, R., McCray, G. and Leigh, W. 2004. 'Trust building mechanisms utilized in outsourced IS development projects: a case study'. Information \& Management 41 (4): 509528.

Lee, J. 2001. 'The impact of knowledge sharing, organizational capability and partner quality on IS outsourcing success'. Information \& Management 38 (5): 323-335.

Lee, J., Huynh, M. and Hirschheim, R. 2008. 'An integrative model of trust on IT outsourcing: Examining a bilateral perspective'. Information Systems Frontiers, 10 (2):145-163

Levin, D., Cross, L., Abrams, E. and Lesser, E. 2004. 'Trust and knowledge sharing: Critical Combination'. In Lesser, E. And Prusak, L. (ed.) Creating Value with Knowledge. Oxford University Press, Oxford, 36-41.

Levina, N and Vaast, E. 2008. 'Innovating or doing as told? status differences and overlapping boundaries in offshore collaboration. MIS Quarterly, 32(2): 307-332.

Li, C. and Hsieh, C. 2009. 'The impact of knowledge stickiness on knowledge transfer implementation, internalization, and satisfaction for multinational corporations'.

International Journal of Information Management, 29 (6): 425-435 
McEvily, S. and Chakravarthy, B. 2002. 'The persistence of knowledge-based advantage: an empirical test for product performance and technological knowledge'. Strategic Management Journal, 23 (4), 285 - 305

Mirani, R. 2006. 'Client-vendor relationships in offshore applications development: An evolutionary framework'. Information Resources Management Journal, 19 (4): 72-86.

Narteh, B. 2008. 'Knowledge transfer in developed-developing country interfirm collaborations: a conceptual framework'. Journal of Knowledge Management, 21 (1): 78-91.

Oshri, I., Kotlarsky, J. and Willcocks, L. 2007. 'Global software development: exploring socialization and face-to-face meetings in distributed strategic projects'. Journal of Strategic Information Systems, 16 (1): 25-49

Park, J., Suh, H. and Yang, H. 2007. 'Perceived absorptive capacity of individual users in performance of Enterprise Resource Planning (ERP) usage: The case for Korean firms'. Information \& Management, 44 (3): 300-312.

Pawlowski, S. and Robey, D. 2004. 'Bridging the user organizations: knowledge brokering and the work of information technology professionals'. MIS Quarterly, 28 (4): 645-672.

Pérez-Nordtvedt, L., Kedia, B. , Datta, D. and Rasheed, A. 2008. 'Effectiveness and efficiency of cross-border knowledge transfer: an empirical examination'. Journal of Management Studies, 45: 699-729.

Ranft, A. and Lord, M. 2002. 'Acquiring new technologies and capabilities: a ground model of acquisition implementation'. Organization Science, 13 (4): 420-441.

Renzl, B. 2008 'Trust in management and knowledge sharing: the mediating effects of fear and knowledge documentation'. Omega, 36 (2): 206-220.

Salmi, P. and Torkkeli, M. 2009. 'Success factors of interorganizational knowledge transfer: a case of collaborative public-private R\&D project'. International Journal Innovation and Research, 3 (2): 109-125.

Sambamurthy, V. and Subramani, M. 2005. 'Special issues on information technologies and knowledge management'. MIS Quarterly, 29 (1): 1-7.

Sarker, S., Sarker, S., Nicholson, D. and Joshi, K. 2005. 'Knowledge transfer in virtual systems development teams: An exploratory study of four key enablers'. IEEE Transactions on Professional Communication, 48 (2): 201-218.

Schmidt, T. 2010 'Absorptive capacity: one size fits all? A firm-level analysis of absorptive capacity for different kinds of knowledge'. Managerial and Decision Economics, 31: 1-18.

Silverman, D. 2000 'Doing Qualitative Research: A Practical Handbook', Sage, Thousand Oaks, CA, USA.

Srivardhana, T. and Pawlowski, S. 2007. 'ERP systems as an enabler of sustained business process innovation: A knowledge-based view'. The Journal of Strategic Information Systems, 16(1):51-69.

Steensma, H. and Lyles, M. 2000. 'Explaining IJV survival in a transitional economy through social exchange and knowledge-based perspectives. Strategic Management Journal, 21(8): 831-851

Tafti, M. 2007 'IT outsourcing: a knowledge-management perspective'. Issues in Information Systems, VIII (2), pp. 488-493.

Tan, D. 2009. 'Factors related to IT outsourcing result' Journal of Outscoring and Organizational Information Management, 1 (3): 18-26.

Timbrell, G.., Andrews, N., and Gable, G. 2001. 'Impediments to inter-firm transfer of best practice in an enterprise systems context. Proceeding of the $7^{\text {th }}$ Americas Conference on Information Systems, Boston, USA, August 2-5.

Tsang, E. 2002. 'Acquiring knowledge by foreign partners for international joint ventures in a transition economy: Learning-by-doing and learning myopia'. Strategic Management Journal, 23, 835-854.

van Wijk, R., Jansen, J. and Lyles, M. 2008. 'Inter- and intra-organizational knowledge transfer: a meta-analytic review and assessment of its antecedents and consequences'. Journal of Management Studies. 45 (4): 830-853. 
Wang, E., Lin, C., Jiang, J. and Klein, G. 2007. 'Improving enterprise resource planning (ERP) fit to organizational process through knowledge transfer'. International Journal of Information Management, 27(3): 200-212.

Wang, L., Gwebu, K., Wang, J. and Zhu, D. 2008. 'The aftermath of information technology outsourcing: an empirical study of firm performance following outsourcing decisions'. Journal of Information Systems, 22 (1): 125-159.

$\mathrm{Xu}, \mathrm{Q}$. and Ma, C., Zhang, C and Su, M. 2006. ' The mediation effect of transfer activities in ERP knowledge transfer'. Proceeding of 15th International Conference on Management of Technology (IAMOT), Beijing, China, May $22-26$.

$\mathrm{Xu}, \mathrm{Q}$. and Ma, Q. 2008. 'Determinants of ERP implementation knowledge transfer'. Information \& Management, 45 (8): 528-538.

Zahra, S. and George, G. 2002. 'Absorptive Capacity: A review, reconceptualization, and extension. The Academy of Management Review, 27 (2): 185-203. 